\title{
Desenvolvimento de bebida mista à base de água de coco e suco de acerola
}

\author{
Development of a blended beverage consisting of coconut water and acerola juice
}

\author{
Andréa da Silva LIMA ${ }^{1}$, Geraldo Arraes MAIA ${ }^{1 \star}$, Paulo Henrique Machado de SOUSA ${ }^{1}$, \\ Fernanda Vanessa Gomes da SILVA ${ }^{1}$, Evânia Altina Teixeira de FIGUEIREDO ${ }^{1}$
}

\section{Resumo}

Levando-se em consideração o grande potencial de industrialização da água de coco e do suco de acerola e suas propriedades funcionais, o presente trabalho teve como objetivo elaborar uma bebida mista à base de água de coco e suco de acerola, na forma "pronto para beber", e avaliar sua estabilidade durante 180 dias de armazenamento à temperatura ambiente $\left(28 \pm 2{ }^{\circ} \mathrm{C}\right)$. Foram preparadas quatro formulações com duas proporções de suco de acerola $(25$ e $30 \%)$ e sólidos solúveis $\left(10\right.$ e $\left.12^{\circ} \mathrm{Brix}\right)$, submetidas ao tratamento térmico a $90{ }^{\circ} \mathrm{C}$ durante 60 segundos e envasadas a quente em garrafas de vidro. As formulações foram submetidas à caracterização química e físico-química (pH, acidez, sólidos solúveis e vitamina C) e avaliação sensorial (cor, sabor e avaliação global). A formulação mais aceita foi avaliada através de análises químicas, físico-químicas, sensoriais e microbiológicas durante 180 dias de armazenamento. A bebida elaborada com $30 \%$ de suco de acerola e adicionada de sacarose até $12^{\circ}$ Brix obteve as maiores notas de aceitação para o sabor e avaliação global quando comparada às demais formulações estudadas. A bebida mista apresentou $\mathrm{pH}$, acidez, sólidos solúveis e açúcares totais estáveis. Os conteúdos de vitamina $\mathrm{C}$, antocianinas totais, açúcares redutores e cor variaram significativamente ao longo de 180 dias de armazenamento. A bebida formulada manteve estabilidade microbiológica. A avaliação sensorial mostrou que a bebida teve boa aceitação pelos provadores, principalmente durante os primeiros 90 dias de armazenamento.

Palavras-chave: mistura; frutas tropicais; Cocus nucifera L.; Malpighia emarginata D. C.; estabilidade.

\begin{abstract}
Considering the great industrialization potential of coconut water and acerola juice and their functional properties, the objective of this work was to develop a ready-to-drink blended beverage based on coconut water and acerola juice and to evaluate its storage stability during 180 days at room temperature $\left(28 \pm 2{ }^{\circ} \mathrm{C}\right)$. Four formulations with 25 and $30 \%$ proportions of juice and total soluble solids $\left(10\right.$ and $\left.12^{\circ} \mathrm{Brix}\right)$ were prepared, heated to $90{ }^{\circ} \mathrm{C}$ for 60 seconds and packed in glass bottles. The samples were submitted to chemical and physicochemical characterization ( $\mathrm{pH}$, acidity, soluble solids and vitamin $\mathrm{C}$ ) and sensory evaluation (color, flavor and global evaluation). The best formulation was evaluated through chemical, physicochemical, sensorial and microbiological analyses during 180 days of storage. The beverage prepared with $30 \%$ acerola juice and sucrose added up to $12^{\circ}$ Brix presented the highest flavor and global evaluation scores when compared to the other samples. The blended beverage was stable with respect to $\mathrm{pH}$, acidity, soluble solids and total sugars. Vitamin $\mathrm{C}$, total anthocyanins and reducing sugars contents and color changed significantly along the 180 days of storage. The formulated beverage maintained microbiological stability. The sensorial evaluation showed that the blended beverage had good acceptability, especially during the first 90 days of storage. Keywords: blend; tropical fruits; Cocus nucifera L.; Malpighia emarginata D. C.; stability.
\end{abstract}

\section{Introdução}

O hábito do consumo de sucos de frutas processadas tem aumentado no Brasil e no mundo, motivado pela falta de tempo da população em preparar o suco das frutas in natura, pela praticidade oferecida pelos produtos, pela substituição do consumo de bebidas carbonatadas devido ao seu valor nutritivo e pela preocupação com o consumo de alimentos mais saudáveis (MATSUURA; ROLIM, 2002).

As frutas se constituem em fonte de vitaminas, minerais e carboidratos solúveis (MATSUURA; ROLIM, 2002), sendo que algumas possuem teor mais elevado de um ou de outro nutriente. A formulação de bebidas mistas de frutas, na forma "pronto para beber", pode ser utilizada com o intuito de melhorar as características nutricionais de determinados sucos, pela complementação de nutrientes fornecidos por frutas diferentes.
Segundo Folegatti, Matsuura e Ferreira (2002), as bebidas mistas de frutas apresentam uma série de vantagens, como a possibilidade de combinação de diferentes aromas e sabores e a soma de componentes nutricionais, como misturas de água de coco com caju (CARVALHO, 2005) e água de coco com maracujá (BRITO; FARO; MELO FILHO, 2004).

A água de coco corresponde a aproximadamente 25\% do peso do fruto. Sua composição básica apresenta $93 \%$ de água, $5 \%$ de açúcares, além de proteínas, vitaminas e sais minerais. É uma bebida leve, refrescante e pouco calórica (ARAGÃO, 2000). Segundo Medina, Garcia e Martin (1980) e Aleixo et al. (2000), é rica em minerais e aminoácidos. Seu consumo vem crescendo nos últimos tempos, principalmente devido às suas propriedades de reposição de eletrólitos perdi-

Recebido para publicação em 4/6/2007

Aceito para publicação em 4/3/2008 (002572)

'Departamento de Tecnologia de Alimentos, Universidade Federal do Ceará - UFC, Av. Mister Hull, 2977, Campus do Pici, CP 12168, CEP 60356-000, Fortaleza - CE, Brasil, E-mail:gmaia@secrel.com.br

${ }^{*}$ A quem a correspondência deve ser enviada 
dos após uma desidratação ou desgaste físico (PENHA, 1998). Segundo Magalhães et al. (2004), a água de coco, apesar de bem aceita, ainda é uma bebida nova no mercado brasileiro e quase desconhecida no mercado internacional, representando um bom potencial a ser explorado.

Pelo seu inegável potencial como fonte natural de vitamina C e sua grande capacidade de aproveitamento industrial, a acerola vem despertando grande interesse por parte de consumidores, produtores, industriais e exportadores (NOGUEIRA et al., 2002; PAIVA; ALVES; BARROS, 1999). A acerola também é fonte de carotenóides precursores da vitamina A e é rica em fitoquímicos, como os flavonóides (antocianinas). As antocianinas e carotenóides são pigmentos antioxidantes que quando combinados são responsáveis pela coloração vermelha dos frutos da aceroleira (LIMA; MÉLO; MACIEL, 2003). Segundo Matsuura e Rolim (2002), o suco de acerola pode ser usado vantajosamente como agente enriquecedor no processamento de numerosos sucos e néctares de frutos pobres em vitamina $C$.

Apesar da variedade de frutas tropicais com sabores exóticos bastante agradáveis, apresentando potencial mercadológico, são poucos os produtos comerciais de misturas dessas frutas. Neste contexto, o presente trabalho visa desenvolver formulações de bebidas mistas à base de água de coco e suco tropical de acerola, na forma "pronto para beber", visando à seleção de uma formulação final com melhor aceitação sensorial, e avaliar a estabilidade da bebida selecionada com relação às alterações químicas, físico-químicas, sensoriais e microbiológicas, durante 180 dias de armazenamento à temperatura ambiente.

\section{Material e métodos}

\subsection{Matéria-prima}

Foram utilizados cocos verdes (Cocus nucifera L.) da variedade anã, adquiridos no mercado varejista de Fortaleza, provenientes do município cearense de Paraipaba, com idade entre 6 e 8 meses de maturação. O suco tropical de acerola (Malpighia emarginata D. C.) foi fornecido por uma indústria local.

$\mathrm{Na}$ formulação das bebidas foram utilizados: benzoato de sódio P.A. (marca VETEC cód. 50.408) e metabissulfito de sódio P.A. (marca CRQ ref. 10938) como conservadores, e açúcar granulado cristalizado, adquirido no comércio local, para correção do teor de sólidos solúveis ( $\left.{ }^{\circ} \mathrm{Brix}\right)$ das bebidas.

\subsection{Processamento e seleção de formulação para estudo da estabilidade}

Os cocos foram recebidos e classificados quanto a seus atributos de qualidade (cor, uniformidade, grau de maturação, isenção de doenças, etc.), lavados com o auxílio de escovas, enxaguados e imersos em água clorada (100 ppm de cloro ativo) durante 15 minutos, abertos com instrumento próprio em aço inoxidável na parte superior do fruto, tendo sua água extraída e em seguida filtrada para utilização na formulação das bebidas.
As bebidas foram formuladas com 25 e $30 \%$ de suco de acerola. Os teores de sólidos solúveis testados foram de 10 e $12{ }^{\circ}$ Brix. Em seguida, foi feita a adição de benzoato de sódio e metabissulfito de sódio nas concentrações de 200 mg.L $\mathrm{L}^{-1}$ e $40 \mathrm{mg} . \mathrm{L}^{-1}$, respectivamente. As bebidas, após formulação, foram submetidas a tratamento térmico tipo hot fill, aquecidas a $90{ }^{\circ} \mathrm{C}$ por 60 segundos, envasadas a quente em garrafas de vidro de $250 \mathrm{~mL}$ e fechadas com tampas plásticas com lacre. Em seguida, as garrafas foram resfriadas por aspersão de água clorada $(100 \mathrm{ppm})$, rotuladas e armazenadas à temperatura ambiente $\left(28 \pm 2{ }^{\circ} \mathrm{C}\right)$.

As análises químicas e físico-químicas $(\mathrm{pH}$, acidez total titulável, vitamina $\mathrm{C}$ e sólidos solúveis) foram realizadas em triplicata em todas as formulações para caracterização de cada bebida. As quatro formulações em estudo foram submetidas à análise sensorial avaliando-se atributos de sabor, cor e avaliação global, a fim de selecionar a formulação mais aceita por parte dos consumidores potenciais.

\subsection{Análise dos resultados da seleção de formulação para estudo da estabilidade}

As determinações químicas, físico-químicas e sensoriais da etapa de seleção da formulação foram avaliadas através de análise de variância (ANOVA), utilizando um delineamento inteiramente casualizado, e quando adequado foi realizado teste de Tukey entre as médias a 95\% de confiança, através do programa estatístico SAS (1999).

\subsection{Formulação e avaliação da estabilidade}

A formulação mais aceita, elaborada com $30 \%$ de suco de acerola e adicionada de sacarose até $12^{\circ} \mathrm{Brix}$ foi formulada novamente de acordo com o item 2.2, armazenada e avaliada após o processamento e a cada 45 dias, ao longo de 180 dias de estocagem, através de análises químicas, físico-químicas, sensoriais e microbiológicas.

\subsection{Determinações químicas e físico-químicas}

$\mathrm{O} \mathrm{pH}$ foi determinado através de leitura direta, em potenciômetro HANNA INSTRUMENTS, modelo HI 9321 (calibrado periodicamente com soluções tampão de $\mathrm{pH} 4,0$ e 7,0) conforme AOAC (1992); acidez total titulável (porcentagem de ácido cítrico) determinada por meio da diluição de $1 \mathrm{~g}$ de amostra homogeneizada em $50 \mathrm{~mL}$ de água destilada, e posterior titulação automática com solução de $\mathrm{NaOH} 0,1 \mathrm{~N}$ até viragem com o indicador fenolftaleína (INSTITUTO ADOLFO LUTZ, 2005); sólidos solúveis através de leitura em refratômetro digital ATAGO, modelo PR-101, com escala de 0 a $45^{\circ}$ Brix; açúcares redutores pelo método do ácido dinitrosalicílico (MILLER, 959) e os açúcares totais segundo as normas analíticas do Instituto Adolfo Lutz (2005); teor de vitamina C (mg.100 mL ${ }^{-1}$ de ácido ascórbico) determinado segundo Pearson (1993); cor $(420 \mathrm{~nm})$ conforme metodologia descrita por Ranganna (1977) e antocianinas totais de acordo com o método descrito por Francis (1982). 


\subsection{Avaliação sensorial}

Os testes sensoriais foram realizados em laboratório em cabines individuais com lâmpadas fluorescentes (luz do dia), as amostras foram servidas monadicamente, sob condições controladas no período da manhã ( 9 horas e 30 minutos às 11 horas e 30 minutos), com 40 provadores não treinados, em uma única sessão. Cada indivíduo recebeu uma taça de vidro codificada com números aleatórios de três dígitos, contendo cerca de $30 \mathrm{~mL}$ da amostra, à temperatura usual de consumo (16 a $18{ }^{\circ} \mathrm{C}$ ). A ordem da apresentação das amostras foi completamente balanceada (MACFIE et al., 1989). Os atributos de cor, sabor e avaliação global foram avaliados por meio de um teste em escala hedônica estruturada de nove categorias: 1 - desgostei muitíssimo a 9 - gostei muitíssimo (MEILGAARD et al., 1987).

\subsection{Análises microbiológicas}

As análises microbiológicas foram realizadas utilizando-se as metodologias descritas em Apha (2001) e Silva e Junqueira e Silveira (2001). As análises constaram de contagens de microrganismos aeróbios mesófilos, contagens de bolores e leveduras, determinações de coliformes a 35 e a $45^{\circ} \mathrm{C}$ e detecção de Salmonella sp.

\subsection{Análise dos resultados da estabilidade}

Os resultados do estudo da estabilidade foram avaliados estatisticamente pelo programa Statistical Analysis System for Windows, versão 8 (SAS, 1999), através de análise de variância e análise de regressão.

\section{Resultados e discussão}

\subsection{Seleção da formulação de bebida mista para estudo da estabilidade}

\section{Avaliação química e físico-química}

Pela análise de variância, verificou-se que o $\mathrm{pH}$, a acidez total titulável e o teor de vitamina $\mathrm{C}$ apresentaram diferença estatística significativa a $5 \%$ de probabilidade.

Os valores obtidos para $\mathrm{pH}$ e acidez total titulável praticamente não variaram entre as formulações com a mesma concentração de suco, observando-se que o aumento da proporção de suco de acerola promoveu menores valores de $\mathrm{pH}$, atribuindo-se à acidez elevada deste suco (Tabela 1). As formulações F3 e F4, com maiores proporções de suco de acerola e, conseqüentemente, com maiores teores de vitamina $\mathrm{C}$, não diferindo entre si pelo teste de Tukey a 5\% de probabilidade, mas diferindo das formulações F1 e F2 (Tabela 1).

A utilização de acerola para melhorar o teor de vitamina C em bebidas vem sendo estudada por outros autores. Matsuura e Rolim (2002) utilizaram sucos integrais comerciais pasteurizados e congelados de abacaxi e acerola para formulação de néctares mistos e foram elaborados néctares com $50 \%$ de suco, sendo a participação da acerola nas formulações de
$2,5,5,7,5$ e $10 \%$, com conteúdos de vitamina $\mathrm{C}$ variando de 79,3 a 245,2 mg. $100 \mathrm{~g}^{-1}$. Em um estudo visando à utilização de suco de melancia como base para formulação de misturas de frutas, Mori, Montgomery e Shirose (1997) avaliaram a adição de sucos de abacaxi e acerola ao suco de melancia. Em um estudo para otimização de um néctar de manga enriquecido com acerola, Matsuura et al. (1999) utilizaram metodologia de superfície de resposta e mapa de preferência, onde foi indicado que a região ótima de aceitação situou-se próxima a $20 \%$ de adição de acerola e $11 \%$ de açúcar (15,3 Brix, 0,50\% de acidez e 76 mg de ácido ascórbico por 100 g).

\section{Avaliação sensorial}

$\mathrm{Na}$ avaliação sensorial, somente a avaliação global apresentou diferença estatística significativa a 5\% de probabilidade.

Em análise comparativa entre as formulações, as médias para avaliação global diferiram estatisticamente a 5\% de significância pelo teste de Tukey (Tabela 2). Para os atributos de sabor, cor e avaliação global as médias em todas as formulações testadas situaram-se entre as notas "não gostei nem desgostei" e "gostei moderadamente". A formulação F4 apresentou a maior média para a avaliação global, estando entre "gostei ligeiramente e gostei moderadamente". A média de sabor também foi maior na formulação F4. Somente na cor a formulação F4 não apresentou a maior média, ficando atrás da formulação F2, porém, apresentaram valores estatisticamente iguais.

No conjunto dos atributos, observou-se uma melhor aceitação da formulação F4 (30\% de suco de acerola e sacarose até $12^{\circ}$ Brix), visto ter sido a que obteve as maiores notas de aceitação para o sabor e avaliação global quando comparada às demais formulações estudadas (Tabela 2), além de ser a formulação que apresentou maior teor de vitamina C (Tabela 1). Diante destes fatos, a formulação F4 foi a escolhida para a elaboração do produto final e estudo da estabilidade.

Tabela 1. Caracterização química e físico-química das formulações de bebidas mistas.

\begin{tabular}{lrrrr}
\hline \multirow{2}{*}{ Parâmetro } & \multicolumn{4}{c}{ Formulação } \\
\cline { 2 - 5 } & \multicolumn{1}{c}{ F1 } & \multicolumn{1}{c}{ F2 } & \multicolumn{1}{c}{ F3 } & \multicolumn{1}{c}{ F4 } \\
\hline pH & $3,45^{\mathrm{a}}$ & $3,45^{\mathrm{a}}$ & $3,38^{\mathrm{b}}$ & $3,38^{\mathrm{b}}$ \\
Acidez total titulável (g.100 mL $\left.\mathrm{mL}^{-1}\right)$ & $0,50^{\mathrm{a}}$ & $0,50^{\mathrm{a}}$ & $0,44^{\mathrm{b}}$ & $0,45^{\mathrm{b}}$ \\
Vitamina C (mg.100 $\left.\mathrm{mL}^{-1}\right)$ & $351,39^{\mathrm{a}}$ & $354,43^{\mathrm{a}}$ & $394,99^{\mathrm{b}}$ & $400,49^{\mathrm{b}}$ \\
\hline
\end{tabular}

F1 (25\% de suco de acerola e $\left.10^{\circ} \mathrm{Brix}\right)$; F2 (25\% de suco de acerola e $\left.12{ }^{\circ} \mathrm{Brix}\right)$; F3 (30\% de suco de acerola e $\left.10^{\circ} \mathrm{Brix}\right)$; e F4 (30\% de suco de acerola e $\left.12{ }^{\circ} \mathrm{Brix}\right)$.

Tabela 2. Análise comparativa de aceitação entre as formulações testadas para mistura de água de coco e suco de acerola.

\begin{tabular}{lcccc}
\hline \multirow{2}{*}{ Atributos } & \multicolumn{4}{c}{ Formulação } \\
\cline { 2 - 5 } & F1 & F2 & F3 & F4 \\
\hline Sabor & $5,70^{\mathrm{a}}$ & $5,32^{\mathrm{a}}$ & $5,20^{\mathrm{a}}$ & $6,12^{\mathrm{a}}$ \\
Cor & $5,85^{\mathrm{a}}$ & $6,15^{\mathrm{a}}$ & $5,98^{\mathrm{a}}$ & $6,00^{\mathrm{a}}$ \\
Avaliação global & $5,25^{\mathrm{b}}$ & $5,62^{\mathrm{b}}$ & $6,10^{\mathrm{a}, \mathrm{b}}$ & $6,85^{\mathrm{a}}$ \\
\hline
\end{tabular}

Valores na mesma linha seguidos da mesma letra não diferem significativamente entre si pelo teste de Tukey a $5 \%$ de probabilidade $(\mathrm{p} \leq 0,05)$. F1 ( $25 \%$ de suco de acerola e $\left.10^{\circ} \mathrm{Brix}\right)$ F2 (25\% de suco de acerola e $\left.12^{\circ} \mathrm{Brix}\right)$; F3 (30\% de suco de acerola e $\left.10^{\circ} \mathrm{Brix}\right)$; e F4 (30\% de suco de acerola e $12^{\circ} \mathrm{Brix}$ ). 


\subsection{Estudo de estabilidade da bebida mista selecionada}

\section{Estabilidade química e físico-química}

A análise estatística mostrou que as variáveis sólidos solúveis, $\mathrm{pH}$, acidez total titulável e açúcares totais não apresentaram correlação significativa para os modelos lineares e quadráticos com o tempo de armazenamento a 95\% de confiança $(\mathrm{p}>0,05)$ (Tabela 3$)$.

Os valores médios de sólidos solúveis variaram entre 11,93 e $12,15^{\circ}$ Brix durante os 180 dias de armazenamento (Figura 1). A estabilidade dos sólidos solúveis totais durante o período de armazenamento também foi constatada por Carvalho (2005), em bebida mista à base de água de coco e suco de caju acondicionada em garrafas de vidro e armazenada à temperatura ambiente $\left(28 \pm 2^{\circ} \mathrm{C}\right)$. Carvalho e Guerra (1995) também verificaram valores constantes em suco integral de acerola quando acondicionado em garrafas de vidro e mantido à temperatura ambiente.

A estabilidade dos valores de $\mathrm{pH}$ (Figura 2) e a acidez total titulável (Figura 3) indicaram que os ácidos orgânicos presentes na bebida de fruta não sofreram oxidações com o decorrer do tempo de armazenamento.

Apesar de não ter sido verificada diferença estatística no teor de açúcares totais com o período de armazenamento, os valores de açúcares redutores apresentaram diferença significativa a 95\% de confiança ( $\mathrm{p} \leq 0,05)$, indicando aumento dos açúcares redutores com o tempo (Figura 4). Esta variação pode ser atribuída à hidrólise dos açúcares não redutores (sacarose) utilizados na padronização dos sólidos solúveis da bebida, que em solução aquosa e em meio ácido é facilmente hidrolisada em monossacarídeos redutores $\mathrm{D}$-glucose e $\mathrm{D}$-frutose (BOBBIO; BOBBIO, 1992). Os valores obtidos variaram do tempo zero ao tempo 180 dias de 5,81 a 7,91\% de glicose, indicando um aumento nos teores de açúcares redutores da ordem de $36,14 \%$.

Carvalho e Guerra (1995) constataram a manutenção da estabilidade dos açúcares totais durante 150 dias de armazenamento a $28^{\circ} \mathrm{C}$, em garrafa de vidro, do suco tropical de acerola, o que também foi observado por Maia et al. (2003), que avaliou uma bebida de baixa caloria à base de acerola (25\%), em garrafa de vidro, pasteurizada e armazenada por 120 dias a $25^{\circ} \mathrm{C}$.

A avaliação estatística da cor expressa em absorbância relativa demonstrou que houve diferença significativa $(\mathrm{p} \leq 0,05)$ durante o período de armazenamento (Figura 5). Os valores das médias variaram entre 0,188 a 0,250 , portanto, constatou-se um aumento da absorbância com o decorrer do armazenamento, in-

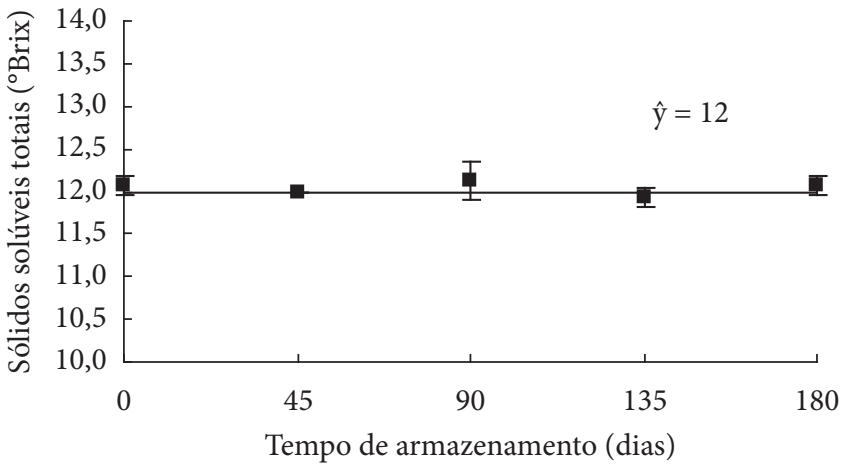

Figura 1. Variação do teor de sólidos solúveis totais da bebida mista F4 em função do tempo de armazenamento.

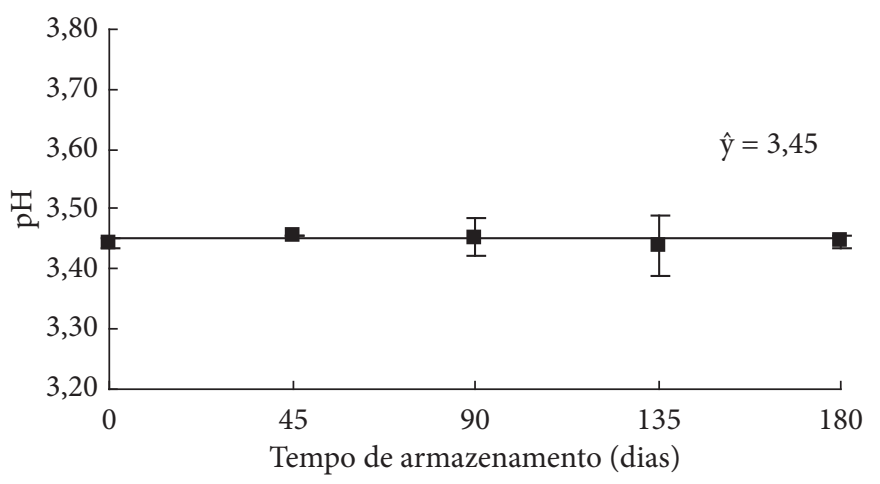

Figura 2. Variação do pH da bebida mista F4 em função do tempo de armazenamento.

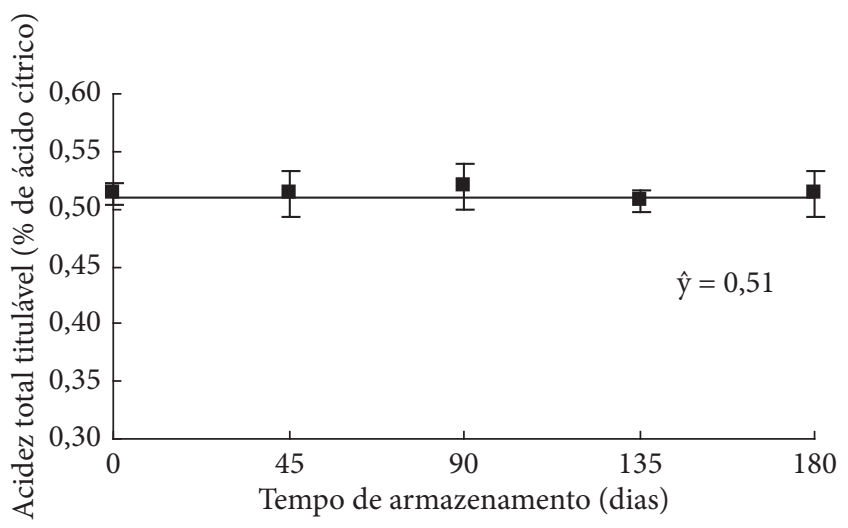

Figura 3. Variação da acidez total titulável da bebida mista F4 em função do tempo de armazenamento.

Tabela 3. Resumo da análise de regressão dos modelos obtidos para Sólidos Solúveis Totais (SST), pH, acidez, Açúcares Redutores (AR) e totais (AT), vitamina C, cor e antocianinas para bebida de água de coco e suco de acerola ao longo do armazenamento.

\begin{tabular}{lccccccccc}
\hline Fonte de variação & GL & \multicolumn{9}{c}{ Quadrado médio } \\
\cline { 3 - 9 } & & SST & $\mathrm{pH}$ & Acidez & AR & AT & Vitamina C & Cor & Antocianinas \\
\hline Linear & 1 & $0,001^{\mathrm{NS}}$ & $<0,001^{\mathrm{NS}}$ & $<0,001^{\mathrm{NS}}$ & $7,361^{*}$ & $0,004^{\mathrm{NS}}$ & $78827,628^{*}$ & $0,0060^{*}$ & $0,0011^{*}$ \\
Falta de ajuste & 3 & $0,023^{\mathrm{NS}}$ & $<0,001^{\mathrm{NS}}$ & $<0,001^{\mathrm{NS}}$ & $0,073^{*}$ & $0,004^{\mathrm{NS}}$ & $59,758^{\mathrm{NS}}$ & $<0,001^{\mathrm{NS}}$ & $<0,001^{\mathrm{NS}}$ \\
Quadrático & 2 & $0,001^{\mathrm{NS}}$ & $<0,001^{\mathrm{NS}}$ & $<0,001^{\mathrm{NS}}$ & $3,715^{*}$ & $0,006^{\mathrm{NS}}$ & $39423,881^{\mathrm{NS}}$ & $0,006^{*}$ & $<0,001^{\mathrm{NS}}$ \\
Falta de ajuste & 2 & $0,034^{\mathrm{NS}}$ & $<0,001^{\mathrm{NS}}$ & $<0,001^{\mathrm{NS}}$ & $0,765^{*}$ & $0,001^{\mathrm{NS}}$ & $80,169^{\mathrm{NS}}$ & $<0,001^{\mathrm{NS}}$ & $<0,001^{\mathrm{NS}}$ \\
\hline
\end{tabular}

${ }^{*}$ Significativos a $5 \%$ de probabilidade; $\mathrm{e}^{\mathrm{NS}} \mathrm{F}$ não significativo a $5 \%$ de probabilidade. 
dicando uma leve tendência ao escurecimento da bebida devido provavelmente a processos enzimáticos e não enzimáticos. Uma suposta regeneração de enzimas no suco podia ter contribuído para o aumento da cor, através do escurecimento enzimático. Schweiggert, Schieber e Carle (2005) e Bahçeci et al. (2005), trabalhando com a atividade da peroxidase (POD) em diversos tecidos de frutas e hortaliças observaram regeneração da POD em diferentes temperaturas.

Os valores obtidos para o teor de vitamina $\mathrm{C}$ apresentaram diferença significativa $(\mathrm{p} \leq 0,05)$ com o decorrer do tempo de armazenamento da bebida (Figura 6). As médias de vitamina $\mathrm{C}$

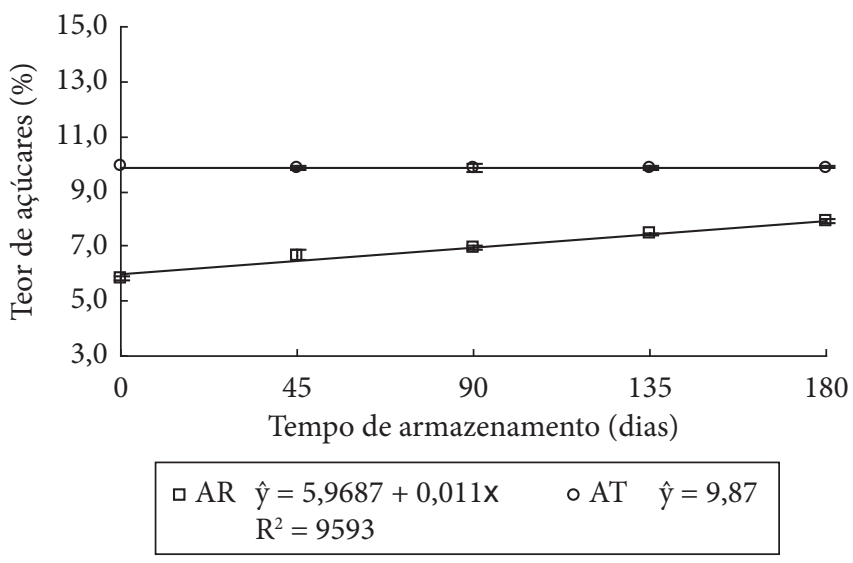

Figura 4. Variação do teor de Açúcares Redutores (AR) e Açúcares Totais (AT) da bebida mista F4 em função do tempo de armazenamento.

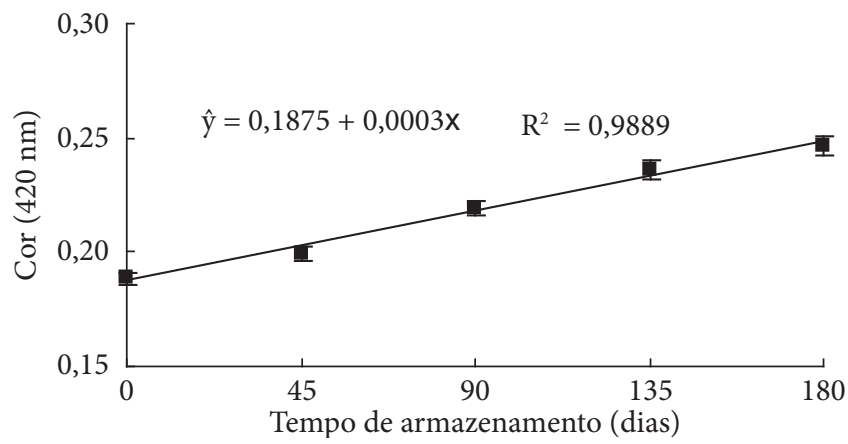

Figura 5. Variação da cor da bebida mista F4 em função do tempo de armazenamento.

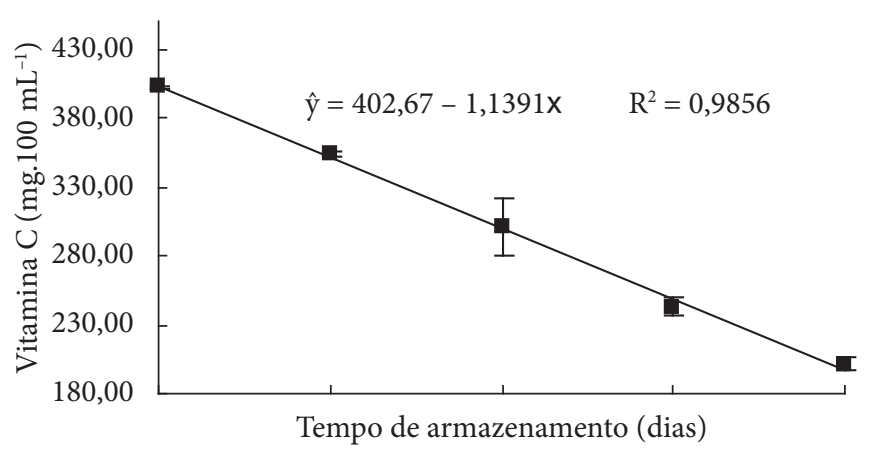

Figura 6. Variação do teor de vitamina C da bebida mista F4 em função do tempo de armazenamento. oscilaram entre 402,23 a 201,44 mg. $100 \mathrm{~mL}^{-1}$ ao longo do armazenamento, indicando uma redução nos teores de vitamina $\mathrm{C}$ da ordem de 49,92\%. O decréscimo da vitamina C apresentou um comportamento linear com o tempo de estocagem, que pode estar associado à temperatura de armazenamento $\left(28 \pm 2^{\circ} \mathrm{C}\right) \mathrm{re}-$ lativamente alta, à exposição da bebida à luz (garrafas de vidro), às reações de oxidação devido ao oxigênio presente no interior da embalagem bem como ao oxigênio dissolvido na bebida, $\mathrm{e}$ à possível ocorrência de reações entre o ácido ascórbico e as antocianinas, com formação de pigmentos. Uma causa adicional da depleção do ácido ascórbico é seu consumo como reagente da reação de Maillard (DJILAS; MILIC, 1994).

Brito, Faro e Melo Filho (2004) observaram uma perda de $77,87 \%$ de ácido ascórbico em néctar elaborado com água de coco seco e suco de maracujá. Carvalho e Guerra (1995) também observaram uma perda de $36,44 \%$ de ácido ascórbico em suco de acerola integral, armazenado por 150 dias a $28{ }^{\circ} \mathrm{C}$. Maia et al. (2003), ao avaliarem a estabilidade de uma bebida de baixa caloria à base de acerola, constataram uma redução de $16,87 \%$ no teor de vitamina C após 120 dias de estocagem a $25^{\circ} \mathrm{C}$.

Sabendo que para adultos a Ingestão Diária Recomendada (IDR) de vitamina C é de 45 mg (BRASIL, 2005), pode-se observar que apesar da grande perda de vitamina $\mathrm{C}$ após 180 dias de armazenamento, uma porção de $100 \mathrm{~mL}$ da bebida ainda fornecia $447,64 \%$ da IDR, caracterizando este produto como excelente fonte dessa vitamina.

Os valores obtidos para o teor de antocianinas totais apresentaram diferença significativa $(\mathrm{p} \leq 0,05)$ com o decorrer do tempo de estocagem (Figura 7), apresentando comportamento linear. Constatou-se, ao final de 180 dias, a completa degradação das antocianinas totais. A perda pode ser devido a interações das antocianinas com o ácido ascórbico e à natureza da embalagem de vidro transparente, que permite a incidência de luz sobre as antocianinas. Segundo Talcott et al. (2003), a interação de antocianinas com ácido ascórbico em presença de oxigênio causa a degradação de ambos os compostos, com descoloração dos pigmentos, o que também ocorre em presença de aminoácidos, fenóis e derivados de açúcar. Portanto, a degradação das antocianinas e do ácido ascórbico ocorre simultaneamente em sucos de frutas, podendo ocorrer durante o processamento e a

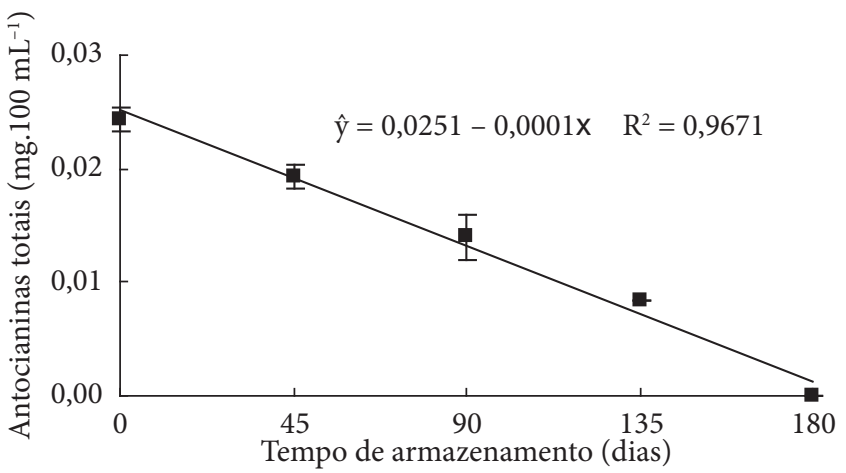

Figura 7. Variação do teor de antocianinas totais da bebida mista F4 em função do tempo de armazenamento. 
estocagem de alimentos. As perdas da coloração das antocianinas podem ser prevenidas através do controle restrito de oxigênio durante o processamento ou através da estabilização física das antocianinas por meio da adição de cofatores antociânicos exógenos, formando copigmentos mais estáveis ao processamento, melhorando atributos de cor, estabilidade e até mesmo incremento das propriedades antioxidantes (BOULTON, 2001). Esses complexos de copigmentos são formados preferencialmente sob condições ácidas.

\section{Estabilidade sensorial}

Os atributos sensoriais de cor, sabor e avaliação global apresentaram correlação significativa com o tempo de armazenamento a $95 \%$ de confiança ( $\mathrm{p} \leq 0,05)$ (Tabela 4), porém o modelo para avaliação global não pode ser ajustado, pois um de seus coeficientes de correlação não foi significativo a $5 \%$ de probabilidade de acordo com o teste $T$.

As médias para a cor variaram entre 5 - nem gostei nem desgostei a 7 - gostei moderadamente Verificou-se que com o aumento da cor instrumental, houve um decréscimo das notas sensoriais de cor por parte dos provadores, indicando que estes perceberam a variação da coloração com o tempo de armazenamento. Com relação ao sabor, as médias situaramse entre os valores 6,8 e 5,7, valores situados entre os termos hedônicos gostei moderadamente e nem gostei nem desgostei, respectivamente. As médias para a avaliação global se situaram entre 7,0 e 5,5, o que corresponde na escala hedônica a gostei moderadamente e não gostei nem desgostei, respectivamente. Ainda verificou-se que até 90 dias de armazenamento praticamente não houve diferença entre os valores médios para a avaliação global, estando as notas próximas ao termo hedônico gostei moderadamente (Figura 8).

De um modo geral, pode ser observado que em todos os atributos, as médias se mantiveram na faixa de aceitação, não ocorrendo redução brusca das médias nos tempos finais de armazenamento, indicando, portanto, boa aceitação sensorial por parte dos consumidores em todo o período estudado.

\section{Estabilidade microbiológica}

As bebidas mistas avaliadas logo após o processamento (tempo zero) e durante os 180 dias de armazenamento apresentaram contagens de microrganismos aeróbios mesófilos, bolores e leveduras inferiores a 10 UFC. $\mathrm{mL}^{-1}$, valores de coliformes a 35 e a $45^{\circ} \mathrm{C}$ inferiores a 2,2 NMP.50 $\mathrm{mL}^{-1}$. Não foi detectada a presença de Salmonella sp. nas amostras avaliadas, estando portanto de acordo com a legislação federal vigente (BRASIL, 2001). A qualidade microbiológica do produto indicou que as condições higiênico-sanitárias de processamento foram satisfatórias e que o tratamento térmico realizado e a presença de aditivos como benzoato de sódio (200 ppm) e metabissulfito de sódio (40 ppm), nestas concentrações, foram eficientes para a conservação do produto por um período de 180 dias, mantidos à temperatura ambiente $\left(28^{\circ} \mathrm{C}\right)$.
Tabela 4. Resumo da análise de regressão dos modelos obtidos para cor, sabor e avaliação global para bebida de água de coco e suco de acerola ao longo do armazenamento.

\begin{tabular}{lcccc}
\hline \multicolumn{1}{c}{ Fonte de } & GL & \multicolumn{3}{c}{ Quadrado médio } \\
\cline { 3 - 5 } variação & & \multicolumn{1}{c}{ Cor } & Sabor & Avaliação global \\
\hline Linear & 1 & $48,000^{*}$ & $29,7025^{*}$ & $51,8400^{*}$ \\
Falta de ajuste & 3 & $9,943^{*}$ & $2,1225^{\mathrm{NS}}$ & $7,1700^{*}$ \\
Quadrático & 2 & $38,675^{*}$ & $31,353^{\mathrm{NS}}$ & $30,810^{*}$ \\
Falta de ajuste & 2 & $0,74^{\mathrm{NS}}$ & $1,533^{\mathrm{NS}}$ & $5,8657^{\mathrm{NS}}$ \\
\hline *Significativos a 5\% de probabilidade; e e $^{\mathrm{NS}} \mathrm{F}$ não significativo a 5\% de probabilidade.
\end{tabular}

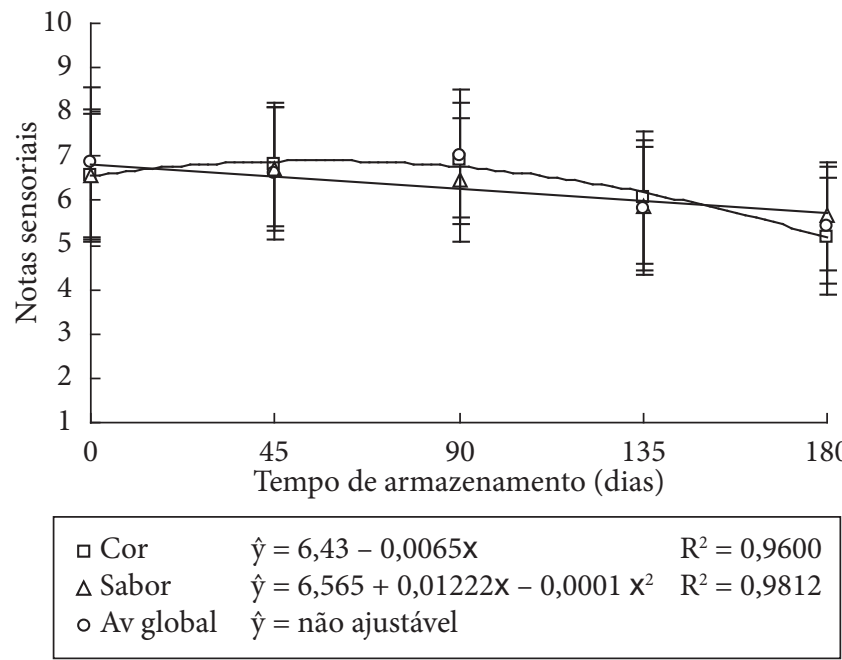

Figura 8. Avaliação da cor (sensorial), sabor e avaliação global da bebida mista F4 em função do tempo de armazenamento.

\section{Conclusões}

A formulação com $30 \%$ de suco de acerola e $12{ }^{\circ}$ Brix foi a mais bem aceita no conjunto dos atributos, além de ser a formulação que apresentou maior teor de vitamina C. Portanto, foi a escolhida para a elaboração do produto final e estudo da estabilidade.

As características químicas e físico-químicas da bebida apresentaram algumas variações ao longo de 180 dias de armazenamento, sendo observada perda excessiva no conteúdo de vitamina $\mathrm{C}$ e a completa degradação das antocianinas.

A bebida formulada manteve uma adequada estabilidade microbiológica durante os 180 dias de armazenamento à temperatura ambiente, indicando boas condições higiênico-sanitárias de processamento, eficiência do tratamento térmico utilizado e efetiva atuação dos aditivos na prevenção do desenvolvimento microbiano.

A avaliação sensorial mostrou que a bebida teve boa aceitação pelos consumidores, principalmente durante os primeiros 90 dias de armazenamento, diminuindo as notas de todos os atributos avaliados (cor, sabor e avaliação global) após este período, porém, a bebida ainda se apresentou dentro da faixa de aceitação.

A mistura de água de coco e suco de acerola é viável na elaboração de bebidas, dentro do processamento utilizado, e pode representar um bom potencial de mercado a ser explorado. 


\section{Agradecimentos}

Ao Conselho Nacional de Desenvolvimento Científico e Tecnológico $(\mathrm{CNPq})$ e à Fundação Cearense de Apoio ao Desenvolvimento Científico e Tecnológico (FUNCAP), pelo suporte financeiro através do fornecimento de bolsas de pesquisa e financiamento da pesquisa.

\section{Referências bibliográficas}

ALEIXO, P. C. et al. Determinação direta de selênio em água de coco e em leite de coco utilizando espectrometria de absorção atômica com atomização eletrotérmica em forno de grafite. Química Nova, v. 23, n. 3, p. 310-312, 2000.

AOAC - Association of Official Analytical Chemistry. Official Methods of Analysis of the Association of Analytical Chemistry. 12 ed. Washington, DC, 1992. 1115p.

APHA - American Public Health Association. DOWNES \& ITO (Coord.). Compendium of Methods for the Microbiological Examination of Foods. 1 ed. Washington, DC, 2001. 676p.

ARAGÃO, W. M. A importância do coqueiro-anão verde. Artigos Embrapa - Coletâneas Rumos \& Debates. Disponível em: $<$ http:// www.embrapa.br:8080/aplic/rumos.nsf/0/85bc576bec325c7c83256 9040048cb84...> Acesso em: 05 out. 2003.

BAHÇECI, K. S. et al Study of lipoxygenase and peroxidase as indicator enzymes in green beans: change of enzyme activity, ascorbic acid and chlorophylls during frozen storage. Journal of Food Engineering, v. 66, n. 2, p. 187-192, 2005.

BOBBIO, F. O.; BOBBIO, F. O. Pigmentos naturais. In: BOBBIO, F. O.; BOBBIO, F. O. (Organizadores). Introdução à química de alimentos. 2 ed. São Paulo: Editora Varela, 1992. p. 191-223.

BOULTON, R. The copigmentation of anthocyanins and its role in the color of red wine: a critical review. American Journal of Enology and Viticulture, v. 52, n. 2, p. 67-86, 2001.

BRASIL. Agência Nacional de Vigilância Sanitária. ANVISA. Ministério da Saúde. Resolução RDC no 12, de 02 de janeiro de 2001. Dispõe sobre os princípios gerais para o estabelecimento de critérios e padrões microbiológicos para alimentos. Diário Oficial da União. Disponível em: <www.anvisa.gov.br> Acesso em: 08 jan. 2005.

BRASIL. Agência Nacional de Vigilância Sanitária. ANVISA. Ministério da Saúde. Resolução RDC nº 269, de 22 de setembro de 2005. Aprova o regulamento técnico sobre a Ingestão Diária Recomendada (IDR) de proteína, vitaminas e minerais. Diário Oficial da União, Poder Executivo, Brasília, 23 de setembro de 2005.

BRito, I. P.; FARO, Z. P.; MELO FILHO, S. C. Néctar de maracujá elaborado com água de coco seco (Cocos nucifera L.). In: CONGRESSO BRASILEIRO DE CIÊNCIA E TECNOLOGIA DE ALIMENTOS, 19, 2004, Recife, PE. Anais... Recife, sbCTA, 2004. (CD-ROM).

CARVALHO, I. T.; GUERRA, N. B. Suco de acerola: estabilidade durante o armazenamento. In: SÃO JOSÉ, A. R.; ALVES, R. E. (Organizadores). Cultura da acerola no Brasil: produção e mercado. Vitória da Conquista: DFZ/UESB, 1995. p. 102-105.

CARVALHO, J. M. Bebidas à base de água de coco e suco de caju: processamento e estabilidade. Fortaleza, 2005. 91 p. Dissertação - (Mestrado em Tecnologia de Alimentos), Departamento de Tecnologia de Alimentos, Universidade Federal do Ceará - UFC.

DJILAS, S. M.; MILIC, B. L. J. Naturally occurring phenolic compounds as inhibitors of free radical formation in the Maillard reaction. In: LABUZA, T. P.; REINECCIUS, G. A.; MONNIER, V. M.;
O'BRIEN, J.; BAYNES, J. W. (Eds). Maillard reaction in chemistry, food and health. The Royal Society of Chemistry, 1994. p. 75-80.

FOLEGATTI, M. I. S.; MATSUURA, F. C. A. U.; FERREIRA, D. C. Otimização da formulação de néctar misto de frutas tropicais através de Metodologia de Superfície de Resposta. In: CONGRESSO BRASILEIRO DE CIÊNCIA E TECNOLOGIA DE ALIMENTOS, 18, 2002, Porto Alegre. Anais... Porto Alegre: sbCTA, 2002. (CD-ROM).

FRANCIS, F. J. Analysis of anthocyanins. In: MARKAKIS, P. (Ed.). Anthocyanins as food colors. New York: Academic Press, 1982. p. 181-207.

INSTITUTO ADOLFO LUTZ. Métodos Físico-Químicos para Análise de Alimentos. Brasília: Ministério da Saúde, Agência Nacional de Vigilância Sanitária, 2005. 1018p.

LIMA, V. L. A.; MÉLO, E. A.; MACIEL, M. I. S. Avaliação do teor de antocianinas em polpa de acerola congelada proveniente de frutos de 12 diferentes aceroleiras (Malpighia emarginata D.C.). Ciência e Tecnologia de Alimentos, v. 23, n. 1, p. 101-103, 2003.

MACFIE, H. J. et al. Designs to balance the effect of order of presentation and first-order carry-over effects in hall tests. Journal of Sensory Studies, v. 4, n. 1, p. 129-148, 1989.

MAGALHÃES, S. C. et al. Estudo comparativo da aceitação de água de coco in natura, refrigerada e industrializada. In: CONGRESSO BRASILEIRO DE CIÊNCIA E TECNOLOGIA DE ALIMENTOS, 19, 2004, Recife. Anais... Recife: [s.n.], 2004.

MAIA, G. A. et al. Obtenção e avaliação de bebida de baixa caloria à base de acerola (Malpighia emarginata D.C.). Revista Ciência Agronômica, v. 34, n. 2, p. 233-240, 2003.

MATSUURA, F. C. A. U. et al. Otimização da aceitação de néctar de manga enriquecido com acerola através de Metodologia de Superfície de Resposta e Mapa de Preferência. In: SIMPÓSIO LATINO AMERICANO DE CIÊNCIA DE ALIMENTOS, 1999, Campinas. Anais... Campinas: Unicamp, 1999. p. 210.

MATSUURA, F. C. A. U.; ROLIM, R. B. Avaliação da adição de suco de acerola em suco de abacaxi visando à produção de um "blend" com alto teor de vitamina C. Revista Brasileira de Fruticultura, v. 24, n. 1, p. 138-141, 2002.

MEDINA, C. J.; GARCIA, J. L. M.; MARTIN, Z. J. Coco: da cultura ao processamento e comercialização. Campinas: Instituto de Tecnologia de Alimentos, 1980. 252 p. (Série Frutas Tropicais).

MEILGAARD, M.; CIVILLE, G. V.; CARR, B. T. Sensory evaluation techniques. Boca Raton: CRC Press, 1987. 159p.

MILLER, G. L. Use of dinitrosalicylic acid reagent for determination of reducing sugars. Analytical Chemistry, v. 31, n. 3, p. 426-429, 1959.

MORI, E. E. M.; MONTGOMERY, M. W.; SHIROSE, I. Análise de um experimento de misturas contendo suco de melancia. Coletânia ITAL, v. 27, n. 1, p. 23-32, 1997.

NOGUEIRA, R. J. M. C. et al. Efeito do estádio de maturação dos frutos nas características físico-químicas de acerola. Pesquisa Agropecuária Brasileira, v. 37, n. 4, p. 463-470, 2002.

PAIVA, J. R.; ALVES, R. E.; BARROS, L. M. Melhoramento genético da aceroleira (Malpighia emarginata D.C.) na Embrapa Agroindústria Tropical. In: Recursos genéticos e melhoramento de plantas para o nordeste brasileiro. Petrolina-PE: Embrapa Semi-Árido; Brasília- DF: Embrapa Recursos Genéticos e Biotecnologia, nov. 1999. Disponível em: <http://www.cpatsa.embrapa.br> Acesso em: 21 março 2004.

PEARSON, D. Técnicas de laboratorio para el análisis de alimentos. 2 ed. Zaragoza: Acríbia, 1993. 331p. 
PENHA, E. M. Características do coco verde para industrialização da água e da polpa gelatinosa. In: CONGRESSO BRASILEIRO DE CIÊNCIA E TECNOLOGIA DE ALIMENTOS: Alimento, população e desenvolvimento. 1998, Rio de Janeiro, RJ. Anais... Rio de Janeiro, RJ: sbCTA, 1998. (CD-ROM).

RANGANNA, M. Manual of analysis of fruit and vegetable products. New Delhi: MacGraw-Hill, 1977. 643p.

SAS Institute, Inc. - STATISTICAL ANALYSIS SYSTEM. SAS User's

Guide: Statistics. Version 5. Cary, NC, 1999.
SCHWEIGGERT, U.; SCHIEBER, A.; CARLE, R. Inactivation of peroxidase, polyphenoloxidase, and lipoxygenase in paprika and chili powder after immediate thermal treatment of the plant material. Innovative Food Science and Emerging Technologies, v. 6, n. 4, p. 403-411, 2005.

SILVA, N.; JUNQUEIRA, V. C. A.; SILVEIRA, N. F. A. Manual de métodos de análise microbiológica de alimentos. 2 ed. São Paulo: Editora Varela, 2001. 229p.

TALCOTT, S. T. et al. Phytochemical stability and color retention of copigmented and processed muscadine grape juice. Journal of Agricultural and Food Chemistry, v. 51, n. 4, p. 957-963, 2003. 